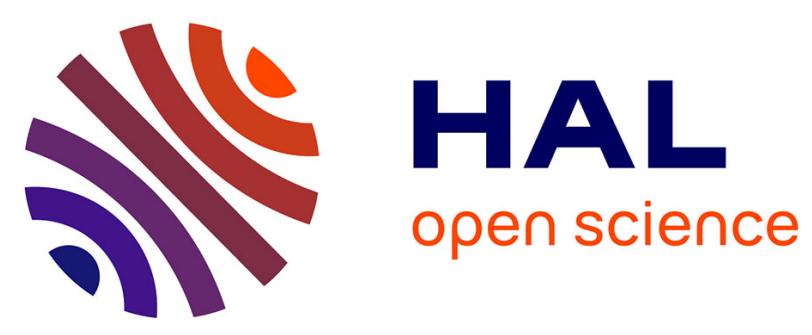

\title{
A novel model for the integrated planning of part quality inspection and preventive maintenance in a linear-deteriorating serial multi-stage manufacturing system
}

Mohammad Rezaei-Malek, Reza Tavakkoli-Moghaddam, Ali Siadat, Jean-Yves

Dantan

\section{To cite this version:}

Mohammad Rezaei-Malek, Reza Tavakkoli-Moghaddam, Ali Siadat, Jean-Yves Dantan. A novel model for the integrated planning of part quality inspection and preventive maintenance in a lineardeteriorating serial multi-stage manufacturing system. International Journal of Advanced Manufacturing Technology, 2018, 96 (9-12), pp.3633-3650. 10.1007/s00170-018-1751-1 . hal-02436779

\section{HAL Id: hal-02436779 \\ https://hal.science/hal-02436779}

Submitted on 13 Jan 2020

HAL is a multi-disciplinary open access archive for the deposit and dissemination of scientific research documents, whether they are published or not. The documents may come from teaching and research institutions in France or abroad, or from public or private research centers.
L'archive ouverte pluridisciplinaire HAL, est destinée au dépôt et à la diffusion de documents scientifiques de niveau recherche, publiés ou non, émanant des établissements d'enseignement et de recherche français ou étrangers, des laboratoires publics ou privés. 


\title{
A novel model for the integrated planning of part quality inspection and preventive maintenance in a linear-deteriorating serial multi-stage manufacturing system
}

\author{
M. Rezaei-Malek ${ }^{1,2}$ 螁 $\cdot$ R. Tavakkoli-Moghaddam ${ }^{1,2} \cdot$ A. Siadat $^{2} \cdot$ J.-Y. Dantan ${ }^{2}$
}

\begin{abstract}
This paper presents a mixed-integer linear mathematical programming model for the integrated planning problem of the part quality inspection and preventive maintenance activities in serial multi-stage manufacturing system. The model concurrently determines the right time and place for performing the above-mentioned activities while the production stages are linearly deteriorating. These two decisions are made while the model is to minimize the total cost including the production, maintenance, inspection, scrap, replacement, and the penalty of shipped defective items to customer(s). A numerical example and a real case study are investigated to validate and verify the proposed model. The results show that the determination of inspection locations along a manufacturing line in different periods of time regarding the impact of preventive maintenance activities on defective production probability results in a more efficient manufacturing system.
\end{abstract}

Keywords Serial multi-stage manufacturing · Linear-deteriorating systems · Preventive maintenance

Part quality inspection · Integrated planning · Mathematical optimization

\section{Introduction}

Manufacturing high-quality products is a significant factor for a company aiming to maintain its global competitiveness. In manufacturing systems (MSs), almost all the production stages are technologically incapable for processing items in a perfect quality. Hence, to increase the guarantee of delivering non-defective products to customer(s), it is required to adopt an effective quality-assurance program by planning and managing resources applied to the inspection and testing of important product quality attributes [1]. Noteworthy, unnecessarily processing of undetected defective items during different downstream production stages results in wasting of materials, equipment, and time [2].

Electronic supplementary material The oniine version of this article (https://doi,org/10.1007/s00170-018-1751-1) contains supplementary material, which is available to authorized users.

M. Rezaei-Malek

m.rezaeimalek@ut.ac.ir; mohammad.rezaeimalek@ensam.eu

1 School of Industrial Engineering, College of Engineering, University of Tehran, Tehran, Iran

2 LCFC, Arts et Métiers Paris Tech, 57078 Metz, France
Such kind of waste, in the present economic environment, has become a major concern for many companies because of its negative effect on the environment and the final production cost [3].

When, where, and how a part quality inspection activity should be implemented in a manufacturing process are significant and challenging decisions in the quality control research area [4]. On the other side, after detection of a defect, the determination of proper defect management strategies including scrap, replacement, rework, and repair allows smoothing the defect propagation throughout a process and to end-consumer(s) [5]. The studies which deal with these questions are classified under the sub-research area of inspection-oriented quality-assurance strategies or in a short form inspection strategies (ISs). An IS tries to allocate an economically appropriate level of part quality inspection by approaching a trade-off among the various cost components, such as inspection, repair, rework, scrap, replacement, and warranty (It takes place when a defective product is shipped to a customer) [1]. The research on the IS problem has been started by Lindsay and Bishop [6]. There are some important review papers in the literature, such as [1, 3, 4, 7], and [8]. The literature of the IS problem can be classified into two main categories according to the 
proposition of Mandroli et al. [1], namely allocation strategy (AS) and parametric strategy (PS). The studies dealing with the question about the location of the part quality inspection activities in MS (e.g., see [9]) are classified as the AS category. The papers attempting to determine proper values for the important parameters such as the fraction of items to be inspected, the number of inspection repetitions, and the frequency of inspections are classified as the PS category (e.g., see [10]). There are some articles, which are concurrently placed in two categories (i.e., AS-PS) (e.g., see [11]).

Maintenance as an important tool for the qualityassurance program, has a strong effect on the optimum inspection strategy. The British Standard Institution defines maintenance as "a combination of all technical and associated administrative activities needed to maintain equipment, installations and other physical assets in the appropriate operating condition or bring them back to this condition" [12]. Maintenance activities in MSs are categorized according to the time that they are activated in. Corrective maintenance is a kind of the maintenance activity which is only activated after a failure has been realized. However, preventive maintenance (PM) is performed to avoid a possible failure. Some of the PM activities are performed in specific points of system lifetime, called time/aged-based maintenance, and the other activities are performed after two or more monitored indicators showing that the system is going to fail or its performance deteriorating (i.e., condition-based maintenance (CBM)). In the CBM strategy, the time for performing a maintenance activity is determined based on the real condition of the system, but in the time/aged-based maintenance, it is based on the historical data of the system [13, 14]. Indeed, different maintenance strategies attempt to preserve the efficiency of degrading resources over time by employing pro-active and predictive capabilities [15].

The system degradation not only increases chance of a failure to happen, but also causes defective product output [16]. Indeed, the previous studies within the ASPS literature just considered a non-deteriorating system with constant defect production probability of different production stages. Although one of the conventional solutions is to conduct the PM activities to reduce the probability of defect production [5], the AS-PS literature lacks a study, which uses the advantage of the PM activities to plan the part quality inspection activities accordingly. Regarding this lack of research, this work attempts to develop a novel integrated optimization approach for the deteriorating serial multi-stage manufacturing systems to improve their efficiency through simultaneously planning of the part quality inspection and PM activities. Briefly, the contribution of the present paper is threefold provided as follows:

- Improving the efficiency of serial multi-stage MSs by presenting an integrated plan for the part quality inspection and PM activities.

- Developing a novel multi-period, mixed-integer, and linear mathematical programming model for a newly defined integrated planning problem.

- Considering the linear-deterioration of production stages and its impact on the right time and place to perform the part quality inspection and PM activities.

The rest of this paper is organized as follows. Section 2 explains the different technical features of the previous articles and specifies the position of this paper in the body of the literature. Then, the contributions of this paper are justified and motivated accordingly. Section 3 describes the problem and provides a non-linear mathematical model for that. Section 4 elaborates the performed linearization process. Section 5 is dedicated to the computational experiment. A real case study is investigated in Section 6. Section 7 draws the conclusions and future research direction.

\section{Literature review}

The AS-PS literature can be reviewed regarding five important features, namely system feature, constraint(s), inspection capability, cost components (i.e., internal failure, external failure, inspection cost, and manufacturing cost), and solution technique. Based on the systems studied in the existing literature, there are three major process configurations regarding the flow of conforming items [1]: serial (e.g., considered at [17] and [18]), assembly (e.g., considered at [19]), and non-serial (e.g., considered at [20]) systems. In a serial MS, input materials pass sequentially the successive processing production stages [3]. There are some papers considered a number of constraints for their optimization problems. Indeed, in the real MSs, there are usually practical constraints for implementing an inspection strategy. For example, Korytkowski [21] studied a production system with the average outgoing quality limit (AOQL) (please refer to [22] for the definition of AOQL). A limit on the budget/number of inspection stations was considered in some studies (see for example, [23-30]).

There are two types of errors (i.e., type-I and type-II) that may happen during a part quality inspection activity. The type-I error means the rejection of good items (e.g., considered at Vaghefi and Sarhangian [31]). The typeII error means the acceptance of non-conformance items (e.g., considered at Deliman and Feldman [32]). For the 
optimization purpose, different cost components can be minimized. The internal failure cost refers to the costs incur inside the company, such as reworking, scrapping, and replacing the detected non-conforming items (e.g., considered at Kimand Gershwin [33]). The external failure costs incur after the defective products are delivered to customer like replacement, repair, and cost of loss of goodwill (e.g., considered at Tayi and Ballou [34]).

The multi-stage structure of an MS leaded most of the papers to apply dynamic programming (DP) as a solution approach (e.g., see Lindsay and Bishop [6] and Freiesleben [35]). However, when the number of production stages increases, because of the formulation complexity, the DP method is not applicable. Therefore, non-exact solution procedures (e.g., heuristics and meta-heuristics) can be employed in this situation [11]. Furthermore, there are some studies employed the simulation technique for performance assessment of the inspection plan while focusing on simple processes to simplify their models (e.g., see Tannock and Saelem [36]). Yum and McDowellj [37] formulated the problem as a 0-1 mixed-linear programming problem. The advantage of this approach is that the problem can be solved by commercially available mixed-integer linear programming (MILP) packages, such as GAMS/Cplex. In addition, the coefficients for this kind of problem can easily be calculated by employing an electronic spread sheet.

Comparing the existing AS-PS literature to the present work, this paper considers a serial multi-stage MS. TypeI and type-II errors can happen during each part quality inspection activity while considering a specific AOQL. The internal and external cost components are considered for the optimization purpose and it formulates the new integrated planning problem as an MILP model and provides the global optimal solution for the system.

We have already mentioned the general features of the present work. Now, we aim at justifying the main contribution of this work, which is the proposition of an integrated optimization approach for the simultaneous planning problem of the part quality inspection and PM activities. For this regard, we first clarify the relation of part quality inspection and PM.

Manufacturing equipment is designed to successfully do operation during the anticipated service life; however, deterioration starts as soon as it is commissioned [12]. Hence, equipment downtime, quality problems, and slower production are the obvious outcomes of this deterioration process. As expressed by Madu [38], equipment maintenance is an important factor affecting the MS's ability to provide quality and timely services to customer. Kuo [16] also mentioned that the degradation of a component/system is one of the major factors that results in defective product output. To decrease the number of defective items, the PM activities should be done on the component/system to maintain it in acceptable conditions in accordance with the product quality requirements [5].

In fact, in the real MSs, when a machine runs, it starts deteriorating after a while and finally it will fail [13]. To be exact, the deterioration process starts when a failure mode is arrived. In the deterioration period, the defective production probability of machine is increasing continuously. Regarding this situation, we should determine, on one side, the appropriate time for doing a PM activity and, on the other side, the right place and appropriate time for doing an inspection. When a maintenance activity is done, the defective production probability of machine is improved. And when you decide to do an inspection activity, you can detect the defects and scrap, rework, or repair them. The second question (i.e., right inspection time and place) is answered in the current AS-PS literature. However, when you face to a changing defective production probability (deteriorating condition) and there is a possibility of doing a PM activity, it is necessary to simultaneously respond to the first (the right time and place of maintenance) and the second question. However, to the best of our knowledge, there is no study for dealing with these two decision problems concurrently.

In comparison to the existing literature, which optimized the inspection plan regardless of the PM effects, integrated planning of part quality inspection and PM activities by applying the proposed approach of this paper increases the efficiency of serial multi-stage MS by producing more conforming items and decreasing the material and energy wastage. On the other side, all the literature have been considered that production stages do not deteriorate in time which is an unrealistic assumption.

\section{Problem description and mathematical formulation}

Consider a serial multi-stage production line (SMSPL). Material enters the SMSPL and passes all the stages and after the last one, it is transformed to a final product ready for selling to customer(s). Each production stage is responsible for a certain quality characteristic. The production stages are technologically incapable for processing items in a perfect quality, so there is a possibility to do an inspection activity (inspection station establishment) after each stage. Each inspection station is capable to detect the defective items associated to the preceding stage and then they can be scrapped or be repaired in a known cost which depends on the processing stage number. There are two types of errors (i.e., type-I and type-II) for each inspection activity.

In the considered SMSPL, each stage is deteriorating in time. To be exact, when a stage starts operating, it starts 


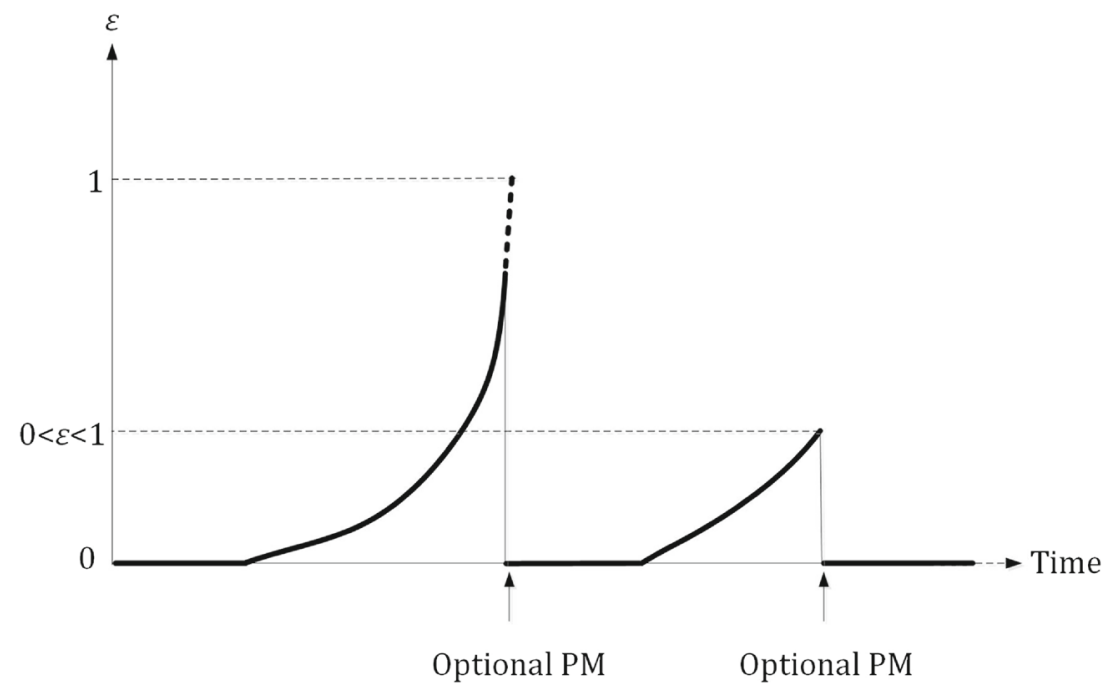

Fig. 1 Impact of the PM on the value of $\varepsilon$

deteriorating after a while and finally it fails. For instance, consider a drill machine, the drill bit becomes blunt after a while and does not have the precise and capability of its beginning. During the deterioration period, probability of a conforming item acquires a defect at a stage, $\varepsilon$, is increasing in time and it is equal to 1 at the end (i.e., the stage fails). Also, it is possible to do a PM activity in a known cost which depends on the extent of remained time to the complete failure. Figure 1 shows an example for the $\varepsilon$ behavior of a stage and the impact of the PM activities on it.

Regarding the above-described SMSPL, the problem is to concurrently plan the part quality inspection and PM activities during a planning horizon while minimizing the total costs (i.e., repair, scrap, production, inspection, maintenance, and penalty of shipped defective items). The planning horizon consists of equal time periods and it is needed to determine in which time periods, inspection, and maintenance activities require to be done. There are $n$ stages and in each period $t$, there is a possibility of doing an inspection and/or PM activity. Figure 2 illustrates the abovementioned problem schematically. Below, we first define the notations and then develop the equivalent mathematical model of the problem.

\subsection{Assumptions}

The main assumptions of the considered problem are as follows:

- A PM activity restores a machine as good as a new one.

- Each stage is deteriorating in time and the probability of defect production is increasing.

- The values of type-I and type-II errors are certain constant quantities during the planning horizon.

- The repair function is done perfectly and transforms the rejected items to the conforming ones.

- Misadjustment error is not considered when a PM activity is done.
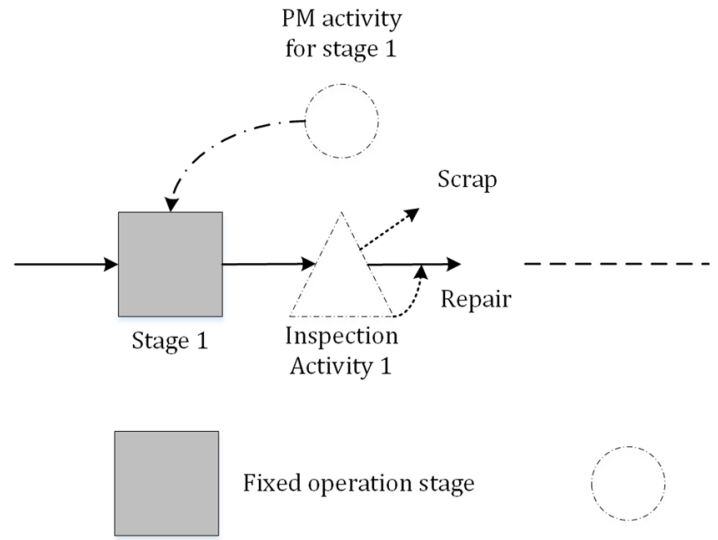

Fixed operation stage

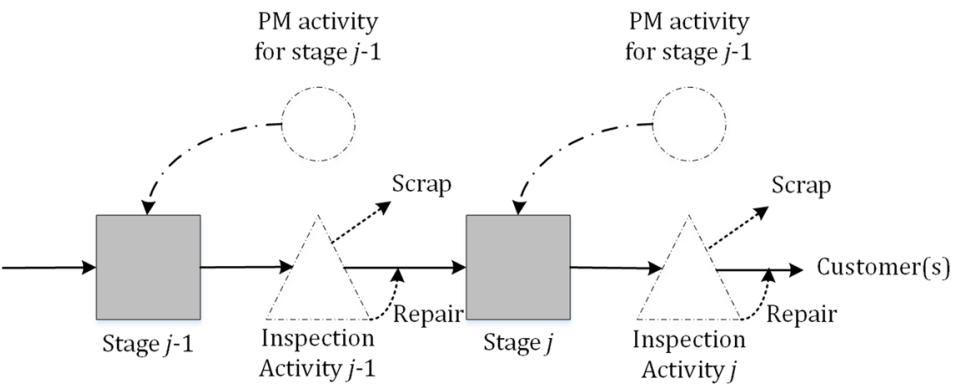

Potential PM activity
Potential inspection activity

Fig. 2 Schematic plan of the considered problem in the sample period $t$ 


\subsection{Indices}

$j \quad$ index of production stages $(j=1, \ldots, n)$

$t \quad$ index of time periods $(t=1, \ldots, T)$

\subsection{Parameters}

$n$ number of production stages in the SMSPL

$w_{t 01}$ number of unit material that enters the SMSPL in the period $t$

$\varepsilon_{t 0} \quad$ non-conforming fraction of material that enters the SMSPL in the period $t$

$p_{0} \quad$ unit material cost entering the SMSPL

$p_{j} \quad$ unit production cost in the stage $j$

$\alpha_{j} \quad$ probability of type-I error at the inspection station $j$

$\beta_{j} \quad$ probability of type-II error at the inspection station $j$

$I_{j} \quad$ unit inspection cost at the inspection station $j$

$f_{j 1}$ fraction of the rejected items repaired at the inspection station $j$

$f_{j 2}$ fraction of the rejected items scraped at the inspection station $j$

$R_{j 1} \quad$ unit replacement/repair cost of a conforming item rejected by the inspection station $j$

$R_{j 2} \quad$ unit replacement/repair cost of a non-conforming item rejected by the inspection station $j$

$S_{j} \quad$ scrap cost per unit in the stage $j$

$C$ penalty cost of delivering a non-conforming item to customer

MQ minimum required number of outgoing conforming item or minimum AOQL

$g(.) \quad \varepsilon_{t j}$ behavior function

$v() \quad. m c_{t j}$ behavior function

\subsection{Variables}

$d_{t j} \quad 1$; if an inspection station associated to the stage $j$ is established in the period $t, 0$; otherwise

$m d_{t j} \quad 1$; if a PM activity associated to the stage $j$ is performed in the beginning of the period $t, 0$; otherwise

$\omega_{t j} \quad$ number of periods have been passed since the last PM activity on the operation stage $j$ in the period $t$

$m c_{t j} \quad$ cost of performing a PM activity for the stage $j$ in the period $t ; m c_{t j}=v\left(\omega_{t j}\right)$

$w_{t j 1} \quad$ expected number of conforming items entering the production stage $j$ in the period $t$

$w_{t, n+1,1}$ expected number of conforming items delivering to customer

$w_{t j 2} \quad$ expected number of non-conforming items entering the production stage $j$ in the period $t$

$w_{t, n+1,2}$ expected number of non-conforming items delivering to customer $u_{t j 1} \quad \alpha_{j}\left(1-\varepsilon_{t j}\right) w_{t j 1} d_{t j}$ expected number of conforming items rejected at the $j$-th inspection station in the period $t$

$u_{t j 2} \quad\left(1-\beta_{j}\right)\left(\varepsilon_{t j} w_{t j 1}+w_{t j 2}\right) d_{t j}$ expected number of non-conforming items rejected at the $j$-th inspection station opportunity in the period $t$

$\varepsilon_{t j} \quad$ probability of a conforming item acquires a defect during processing in the stage $j$ in the period $t ; \varepsilon_{t j}=g\left(\omega_{t j}\right)$

PC total production cost of the SMSPL

IC total inspection cost of the SMSPL

RC total replacement/repair cost of the SMSPL

MC total PM cost of the SMSPL

SC total scrap cost of the SMSPL

EC penalty cost of non-conforming goods shipped to customer

\subsection{Mixed-integer nonlinear mathematical programming model}

Based on the above-mentioned definitions, mixed-integer non-linear mathematical formulation of the problem is provided as follows:

\subsubsection{Model 1}

$\operatorname{Min} z=\mathrm{RC}+\mathrm{SC}+\mathrm{PC}+\mathrm{IC}+\mathrm{MC}+\mathrm{EC}$,

where:

$\mathrm{RC}=\sum_{t=1}^{T} \sum_{j=1}^{n} f_{j 1} R_{j 1} u_{t j 1}+\sum_{t=1}^{T} \sum_{j=1}^{n} f_{j 1} R_{j 2} u_{t j 2}$

$\mathrm{SC}=\sum_{t=1}^{T} \sum_{j=1}^{n} f_{j 2} S_{j} u_{t j 1}+\sum_{t=1}^{T} \sum_{j=1}^{n} f_{j 2} S_{j} u_{t j 2}$

$\mathrm{PC}=\sum_{t=1}^{T} \sum_{j=1}^{n} p_{j}\left(w_{t j 1}+w_{t j 2}\right)$

$\mathrm{IC}=\sum_{t=1}^{T} \sum_{j=1}^{n} I_{j}\left(w_{t j 1}+w_{t j 2}\right) d_{t j}$

$\mathrm{MC}=\sum_{t=1}^{T} \sum_{j=1}^{n} m c_{t j} m d_{t j}$ 


$$
\mathrm{EC}=\sum_{t=1}^{T} C \times w_{t, n+1,2}
$$$$
\text { s.t. }
$$$$
w_{t, 1,1}=\left(1-\varepsilon_{t 0}\right) w_{t 01} \quad \forall t
$$$$
w_{t, 1,2}=\varepsilon_{t 0} w_{t 01} \quad \forall t
$$$$
w_{t, j+1,1}=\left(1-\varepsilon_{t j}\right) w_{t j 1}+\left(f _ { j 1 } \left(\alpha_{j}\left(1-\varepsilon_{t j}\right)\right.\right.
$$$$
\left.\left.+\left(1-\beta_{j}\right) \varepsilon_{t j}\right)-\alpha_{j}\left(1-\varepsilon_{t j}\right)\right) w_{t, j, 1} d_{t j}
$$$$
+f_{j 1}\left(1-\beta_{j}\right) w_{t j 2} d_{t j} \quad \forall t, j \neq n
$$$$
w_{t, n+1,1}=\left(1-\varepsilon_{t n}\right) w_{t n 1}+\left(f _ { n 1 } \left(\alpha_{n}\left(1-\varepsilon_{t n}\right)\right.\right.
$$$$
\left.\left.+\left(1-\beta_{n}\right) \varepsilon_{t n}\right)-\alpha_{n}\left(1-\varepsilon_{t n}\right)\right) w_{t, n, 1} d_{t n}
$$$$
+f_{n 1}\left(1-\beta_{n}\right) w_{t n 2} d_{t n} \quad \forall t
$$$$
w_{t, j+1,2}=w_{t j 2}+\varepsilon_{t j} w_{t j 1}-\left(1-\beta_{j}\right) \varepsilon_{t j} w_{t j 1} d_{t j}
$$$$
-\left(1-\beta_{j}\right) w_{t j 2} d_{t j} \quad \forall t, j
$$$$
\omega_{t j}=\left(\omega_{t-1, j}+1\right)\left(1-m d_{t j}\right) \quad \forall j, t \neq 1
$$$$
\omega_{1 j}=0 \quad \forall j
$$$$
m d_{1 j}=1 \quad \forall j
$$$$
\varepsilon_{t j}=g\left(\omega_{t j}\right) \quad \forall t, j
$$$$
m c_{t j}=v\left(\omega_{t j}\right) \quad \forall t, j
$$$$
w_{t, n+1,1} \geq M Q \quad \forall t
$$

$$
w_{t j 1}, w_{t, n+1,1}, w_{t j 2}, w_{t, n+1,2}, m c_{t j}, u_{t j 1}, u_{t j 2}, \omega_{t j}, \varepsilon_{t j},
$$$$
R C, I C, P C, M C, S C, E C \geq 0 \quad \forall t
$$

$$
m d_{t j}, d_{t j}: \text { binary } \quad \forall t, j
$$

Objective function (1) minimizes the total cost including repair, scrap, production, inspection, PM, and external cost. Equations 2-7 calculate these different cost components. Equations 8-12 calculate the expected number of conforming and non-conforming items entering the different production stages in each period. Equation 13 calculates the number of passed time periods after the last performed PM activity. It is assumed that a PM activity is done for all the production stages in the first period (please see Eqs. 14 and 15). Equation 16 indicates that $\varepsilon$ is a function of the number of passed time periods after the last performed PM activity. Equation 17 calculates the maintenance cost of the stage $j$ in the period $t$ which is a function of $\omega_{t j}$. Constraint (18) is an AOQL restriction, which imposes the SMSPL to produce at least $M Q$ conforming items in each period. Equation 19 is a non-negativity limitation, and equation 20 indicates that opening an inspection station and doing a PM activity are binary decisions.

\section{Methodology}

The presented Model 1 is an MINLP model; however, it can be transformed to an MILP model through employing the conventional operation research linearization techniques. An MILP model can be optimized globally by a branch-and-cut algorithm which solves a series of linear programming subproblems [39]. If an MINLP model cannot transformed to an MILP, it should be solved by the outer approximation/generalized bender's decomposition and branch-and-bound algorithm, which can guarantee the global optimality of the obtained solution in some limited cases (for more information, enthusiastic readers can refer to [40]). In the following, the linearization process through applying some conventional operation research techniques is elaborated.

As it can be seen, there are some terms including the products of binary and non-negative real variables. The linearization procedure is done by adding some new variables and constraints to Model 1 (please see Table 1).

By doing the above-mentioned linearization process, Model 1 is transformed to Model I, which is provided in detail in Supplementary Material. As it is obvious, Model I is still an MINLP model because it includes the product of the variable $\varepsilon_{t j}$ and the other non-negative real variables (i.e., $w_{t j 1}, w d_{t j 1}$, and $w d_{t j 2}$ ). Indeed, it is possible to transform Model I to an MILP model if $\varepsilon_{t j}$ is assumed as a linear function of an integer variable $\omega_{t j}$ (i.e., $\varepsilon_{t j}=g\left(\omega_{t j}\right)=$ $a_{j} \omega_{t j}+b_{j}$, where $a_{j}$ and $b_{j}$ are the parameters of the function). The substitution of $a_{j} \omega_{t j}+b_{j}$ for $\varepsilon_{t j}$ changes the non-linearity form of mathematical terms to which are the product of integer and non-negative real variables. For the planning purposes, the real MSs absolutely have a certain planning horizon, so the upper bound $\left(\omega_{t j}^{\mathrm{UP}}\right)$ and lower bound $\left(\omega_{t j}^{\mathrm{LO}}\right)$ of the integer variable $\omega_{t j}$ are not indeterminable. Regarding this fact, by introduction of binary variables $x_{i t j}\left(i=\omega_{t j}^{\mathrm{LO}}, \ldots, \omega_{t j}^{\mathrm{UP}}\right)$ and using the SOS 1 constraint $\omega_{t j}=\sum_{i=\omega_{t j}^{L O}}^{\omega_{t j}^{\mathrm{UP}}} x_{i t j} i$, products of binary and nonnegative real variables are achieved which are easy to linearize. On the other side, it is needed to linearize the product $\omega_{t-1, j}$ and $m d_{t j}$ when $\omega_{t j}$ is recently considered as an integer variable (please see Table 1 to find the implemented linearization method). Now, these linearization 
Table 1 Linearization process of the products of binary and non-negative real variables

For new variable $w d_{t j 1}=w_{t j 1} \times d_{t j}$,

additional constraints would be as follows:

$w d_{t j 1} \leq M \times d_{t j}$

$w d_{t j 1} \leq w_{t j 1}$

$w d_{t j 1} \geq w_{t j 1}-\left(1-d_{t j}\right) \times M$

$w d_{t j 1} \geq 0$

For new variable $m c d_{t j}=m c_{t j} \times m d_{t j}$, additional constraints would be as follows:

$m c d_{t j} \leq M \times m d_{t j}$

$m c d_{t j} \leq m c_{t j}$

$m c d_{t j} \geq m c_{t j}-\left(1-m d_{t j}\right) \times M$

$m c d_{t j} \geq 0$

For new variable $x w d_{i t j 1}=x_{i t j} \times w d_{t j 1}$,

additional constraints would be as follows:

$x w d_{i t j 1} \leq M \times x_{i t j}$

$x w d_{i t j 1} \leq w d_{t j 1}$

$x w d_{i t j 1} \geq w d_{t j 1}-\left(1-x_{i t j}\right) \times M$

$x w d_{i t j 1} \geq 0$

For new variable $x w_{i t j 1}=x_{i t j} \times w_{t j 1}$,

additional constraints would be as follows:

$x w_{i t j 1} \leq M \times x_{i t j}$

$x w_{i t j 1} \leq w_{t j 1}$

$x w_{i t j 1} \geq w_{t j 1}-\left(1-x_{i t j}\right) \times M$

$x w_{i t j 1} \geq 0$
For new variable $w d_{t j 2}=w_{t j 2} \times d_{t j}$,

additional constraints would be as follows:

$w d_{t j 2} \leq M \times d_{t j}$

$w d_{t j 2} \leq w_{t j 2}$

$w d_{t j 2} \geq w_{t j 2}-\left(1-d_{t j}\right) \times M$

$w d_{t j 2} \geq 0$

For new variable $\omega m d_{t-1, t, j}=\omega_{t-1, j} \times m d_{t j}$,

additional constraints would be as follows:

$\omega m d_{t-1, t, j} \leq M \times m d_{t j}$

$\omega m d_{t-1, t, j} \leq \omega_{t-1, j}$

$\omega m d_{t-1, t, j} \geq \omega_{t-1, j}-\left(1-m d_{t j}\right) \times M$

$\omega m d_{t-1, t, j} \geq 0$

For new variable $x w d_{i t j 2}=x_{i t j} \times w d_{t j 2}$,

additional constraints would be as follows:

$x w d_{i t j 2} \leq M \times x_{i t j}$

$x w d_{i t j 2} \leq w d_{t j 2}$

$x w d_{i t j 2} \geq w d_{t j 2}-\left(1-x_{i t j}\right) \times M$

$x w d_{i t j 2} \geq 0$

For new variable $\omega m d_{t-1, t, j}=\omega_{t-1, j} \times m d_{t j}$,

additional constraints would be as follows

$\omega_{t j}^{L O} \times m d_{t j} \leq \omega m d_{t-1, t, j} \leq \omega_{t j}^{U P} \times m d_{t j}$

$\omega_{t-1, j}-\omega_{t j}^{U P} \times\left(1-m d_{t j}\right) \leq \omega m d_{t-1, t, j} \leq \omega_{t-1, j}-\omega_{t j}^{L O} \times\left(1-m d_{t j}\right)$

$\omega m d_{t-1, t, j} \geq 0$ processes transform the MINLP Model I to an MILP Model 2. For further understanding, the step-by-step linearization process of Model I is provided in Supplementary Material as Model II to Model IV. Briefly, Fig. 3 shows the proposed linearization methodology.

\subsection{Mixed-integer linear mathematical programming model}

\subsubsection{Model 2}

$\operatorname{Min} z=\mathrm{RC}+\mathrm{SC}+\mathrm{PC}+\mathrm{IC}+\mathrm{MC}+\mathrm{EC}$,

where

$$
\begin{aligned}
\mathrm{RC}= & \sum_{t=1}^{T} \sum_{j=1}^{n} f_{j 1} R_{j 1} \alpha_{j} w d_{t j 1}-f_{j 1} R_{j 1} \alpha_{j} a_{j} \\
& \times\left(\sum_{i=\omega_{t j}^{L O}}^{\omega_{t j}^{U P}} x w d_{i t j 1} i\right)-f_{j 1} R_{j 1} \alpha_{j} b_{j} w d_{t j 1} \\
& \sum_{t=1}^{T} \sum_{j=1}^{n} f_{j 1} R_{j 2} a_{j}\left(\sum_{i=\omega_{t j}^{L O}}^{\omega_{t j}^{U P}} x w d_{i t j 1} i\right)
\end{aligned}
$$

$$
\begin{aligned}
& +f_{j 1} R_{j 2} b_{j} w d_{t j 1}+f_{j 1} R_{j 2} \alpha_{j}\left(\sum_{i=\omega_{t j}^{L O}}^{\omega_{t j}^{U P}} x w d_{i t j 2} i\right) \\
& +f_{j 1} R_{j 2} b_{j} w d_{t j 2}-f_{j 1} R_{j 2} \beta_{j} a_{j}\left(\sum_{i=\omega_{t j}^{L O}}^{\omega_{t j}^{U P}} x w d_{i t j 1} i\right) \\
& -f_{j 1} R_{j 2} \beta_{j} b_{j} w d_{t j 1}
\end{aligned}
$$$$
-f_{j 1} R_{j 2} \beta_{j} a_{j}\left(\sum_{i=\omega_{t j}^{L O}}^{\omega_{t j}^{U P}} x w d_{i t j 2} i\right)
$$$$
-f_{j 1} R_{j 2} \beta_{j} b_{j} w d_{t j 2}
$$

$$
\begin{aligned}
\mathrm{SC}= & \sum_{t=1}^{T} \sum_{j=1}^{n} f_{j 2} S_{j} \alpha_{j} w d_{t j 1}-f_{j 2} S_{j} \alpha_{j} a_{j}\left(\sum_{i=\omega_{t j}^{L O}}^{\omega_{t j}^{U P}} x w d_{i t j 1} i\right) \\
& -f_{j 2} S_{j} \alpha_{j} b_{j} w d_{t j 1} \\
& +\sum_{t=1}^{T} \sum_{j=1}^{n} f_{j 2} S_{j} a_{j}\left(\sum_{i=\omega_{t j}^{L O}}^{\omega_{t j}^{U P}} x w d_{i t j 1} i\right)+f_{j 2} S_{j} b_{j} w d_{t j 1}
\end{aligned}
$$




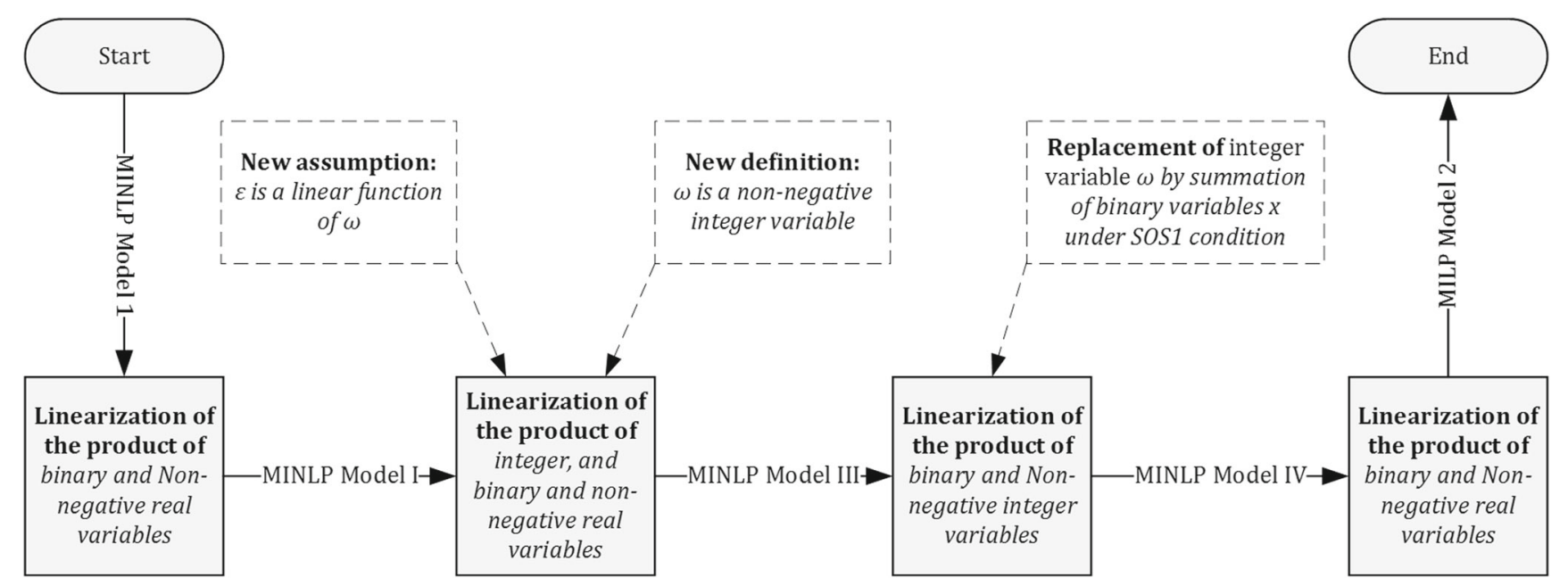

Fig. 3 Proposed methodology

$$
\begin{aligned}
& +f_{j 2} S_{j} a_{j}\left(\sum_{i=\omega_{t j}^{L O}}^{\omega_{t j}^{U P}} x w d_{i t j 2} i\right) \\
& +f_{j 2} S_{j} b_{j} w d_{t j 2}-f_{j 2} S_{j} \beta_{j} a_{j}\left(\sum_{i=\omega_{t j}^{L O}}^{\omega_{t j}^{U P}} x w d_{i t j 1} i\right) \\
& -f_{j 2} S_{j} \beta_{j} b_{j} w d_{t j 1}-f_{j 2} S_{j} \beta_{j} a_{j}\left(\sum_{i=\omega_{t j}^{L O}}^{\omega_{t j}^{U P}} x w d_{i t j 2} i\right) \\
& -f_{j 2} S_{j} \beta_{j} b_{j} w d_{t j 2}
\end{aligned}
$$

$\mathrm{PC}=\sum_{t=1}^{T} \sum_{j=1}^{n} p_{j}\left(w_{t j 1}+w_{t j 2}\right)$

$\mathrm{IC}=\sum_{t=1}^{T} \sum_{j=1}^{n} I_{j}\left(w d_{t j 1}+w d_{t j 2}\right)$

$\mathrm{MC}=\sum_{t=1}^{T} \sum_{j=1}^{n} m c d_{t j}$

$\mathrm{EC}=\sum_{t=1}^{T} C \times w_{t, n+1,2}$

s.t.

$w_{t, 1,1}=\left(1-\varepsilon_{t 0} w_{t 01}\right) \quad \forall t$

$w_{t, 1,2}=\varepsilon_{t 0} w_{t 01} \quad \forall t$

$w_{t, j+1,1}=w_{t j 1}-a_{j}\left(\sum_{i=\omega_{t j}^{L O}}^{\omega_{t j}^{U P}} x w d_{i t j 1} i\right)-b_{j} w_{t j 1}$

$+f_{j 1} \alpha_{j} w d_{t j 1} f_{j 1} \alpha_{j} a_{j}\left(\sum_{i=\omega_{t j}^{L O}}^{\omega_{t j}^{U P}} x w d_{i t j 1} i\right)$

$-f_{j 1} \alpha_{j} b_{j} w d_{t j 1}$

$+f_{j 1} a_{j}\left(\sum_{i=\omega_{t j}^{L O}}^{\omega_{t j}^{U P}} x w d_{i t j 1} i\right)+f_{j 1} b_{j} w d_{t j 1}$

$-f_{j 1} \beta_{j} a_{j}\left(\sum_{i=\omega_{t j}^{L O}}^{\omega_{t j}^{U P}} x w d_{i t j 1} i\right)$

$-f_{j 1} \beta_{j} b_{j} w d_{t j 1}-\alpha_{j} w d_{t j 1}$

$-\alpha_{j} a_{j}\left(\sum_{i=\omega_{t j}^{L O}}^{\omega_{t j}^{U P}} x w d_{i t j 1} i\right)$

$-\alpha_{j} b_{j} w d_{t j 1}+f_{j 1} w d_{t j 2}$

$-f_{j 1} \beta_{j} w d_{t j 2} \quad \forall t, j \neq n$

$w_{t, n+1,1}=w_{t n 1}-a_{n}\left(\sum_{i=\omega_{t n}^{L O}}^{\omega_{t n}^{U P}} x w d_{i t n 1} i\right)-b_{n} w_{t n 1}$

$+f_{n 1} \alpha_{n} w d_{t n 1} f_{n 1} \alpha_{n} a_{n}\left(\sum_{i=\omega_{t n}^{L} O}^{\omega_{t n}^{U P}} x w d_{i t n 1} i\right)$

$-f_{n 1} \alpha_{n} b_{n} w d_{t n 1}$ 


$$
\begin{aligned}
& +f_{n 1} a_{n}\left(\sum_{i=\omega_{t n}^{L O}}^{\omega_{t n}^{U P}} x w d_{i t n 1} i\right)+f_{n 1} b_{n} w d_{t n 1} \\
& -f_{n 1} \beta_{n} a_{n}\left(\sum_{i=\omega_{t n}^{L O}}^{\omega_{t n}^{U P}} x w d_{i t n 1} i\right) \\
& -f_{n 1} \beta_{n} b_{n} w d_{t n 1}-\alpha_{n} w d_{t n 1} \\
& -\alpha_{n} a_{n}\left(\sum_{i=\omega_{t n}^{L O}}^{\omega_{t n}^{U P}} x w d_{i t n} i\right) \\
& -\alpha_{n} b_{n} w d_{t n 1}+f_{n 1} w d_{t n 2}-f_{n 1} \beta_{n} w d_{t n 2} \quad \forall t \\
& w_{t, j+1,2}=w_{t j 2}+a_{j}\left(\sum_{i=\omega_{t n}^{L O}}^{\omega_{t n}^{U P}} x w d_{i t n 1} i\right)+b_{j} w_{t j 1} \\
& -a_{j}\left(\sum_{i=\omega_{t n}^{L O}}^{\omega_{t n}^{U P}} x w d_{i t n 1} i\right)-b_{j} w d_{t j 1} \\
& +\beta_{j} a_{j}\left(\sum_{i=\omega_{t n}^{L O}}^{\omega_{t n}^{U P}} x w d_{i t n 1} i\right)+\beta_{j} b_{j} w d_{t j 1} \\
& -w d_{t j 2}+\beta_{j} w d_{t j 2} \quad \forall t, j \\
& \omega_{t j}=\omega_{t-1, j}+1-\omega m d_{t-1, t, j}+m d_{t j} \quad \forall j, t \neq 1 \\
& \omega_{1 j}=0 \quad \forall j \\
& m d_{1 j}=1 \quad \forall j \\
& \varepsilon_{t j}=g\left(\omega_{t j}\right)=\left(a_{j} \omega_{t j}+b_{j}\right) \quad \forall t, j \\
& m c_{t j}=v\left(\omega_{t j}\right) \quad \forall t, j \\
& w_{t, n+1,1}=M Q \quad \forall t \\
& w d_{t j 1} \leq M \times d_{t j} \quad \forall t, j \\
& w d_{t j 1} \leq w_{t j 1} \quad \forall t, j \\
& w d_{t j 1} \geq w_{t j 1}-\left(1-d_{t j}\right) \times M \quad \forall t, j \\
& w d_{t j 2} \leq M \times d_{t j} \quad \forall t, j \\
& w d_{t j 2} \leq w_{t j 2} \quad \forall t, j \\
& w d_{t j 2} \geq w_{t j 2}-\left(1-d_{t j}\right) \times M \quad \forall t, j
\end{aligned}
$$

$$
\begin{aligned}
& m c d_{t j} \leq M \times m d_{t j} \quad \forall t, j \\
& m c d_{t j} \leq m c_{t j} \quad \forall t, j \\
& m c d_{t j} \geq m c_{t j}-\left(1-m d_{t j}\right) \times M \quad \forall t, j \\
& \omega_{t j}^{L O} \times m d_{t j} \leq \omega m d_{t-1, t, j} \leq \omega_{t j}^{U P} \times m d_{t j} \quad \forall j, t \neq 1 \\
& \omega_{t-1, j}-\omega_{t j}^{U P} \times\left(1-m d_{t j}\right) \leq \omega m d_{t-1, t, j} \leq \omega_{t-1, j} \\
& -\omega_{t j}^{L O} \times\left(1-m d_{t j}\right) \quad \forall j, t \neq 1 \\
& w_{t j 1}, w_{t j 2}, w d_{t j 1}, w d_{t j 2}, m c_{t j}, m c d_{t j}, \varepsilon_{t j}, R C, I C, P C, \\
& M C, S C, E C \geq 0 \quad \forall t \\
& \omega m d_{t-1, t, j} \geq 0 \quad \forall j, t \neq 1 \\
& m d_{t j}, d_{t j} \text { : binary, } \omega_{t j} \text { : Positive integer, } x_{i t j} \text { : binary and } \\
& \text { SOS1 } \forall t, i, j
\end{aligned}
$$

\section{Experimental results}

To show the presented model works well, to provide reasonable results, and to conduct a study on the sensitivity of the presented Model 2 to the critical input parameters, a numerical example is investigated. This example and its specifications are inspired from a real SMSPL which is an assembly line for "PC250" air piston compressors. It includes a three-stage system, in which the duration of the planning horizon is 12 periods. The deterioration processes of all the three stages are the same because the system includes identical machines and tools for doing different operations. Regarding the historical data, the $\varepsilon_{t j}$ behavior of each stage as a function of $\omega_{t j}$ is $\varepsilon_{t j}=0.05 \times \omega_{t j}$. Similarly, the PM cost as a function of $\omega_{t j}$ is $m c_{t j}=50+10 \times \omega_{t j}$. The number of unit material entering the SMSPL is 100 units per period and $5 \%$ of them are non-conforming, i.e., $\varepsilon_{t 0}=0.05$. The cost for replacing a delivered non-conforming item is estimated US\$ 20 and minimum AOQL is 50 units per period, i.e., $\mathrm{MQ}=50$. The rest of input data is provided in Table 2.

Model 2 is coded in the GAMS software (ver. 24.1.2) and solved by the CPLEX solver (ver. 12.5.1.0), which is capable to solve MILP models through the branch-and-cut algorithm, on the data of the numerical example and the case study using a laptop with Corei7 CPU, $1.73 \mathrm{GHz}$, and $4 \mathrm{~GB}$ of RAM.

In comparison with the existing literature, specifically those presented mathematical models for the conventional IS problem (e.g., see Yum and McDowellj [37], Mohammadi et al. [17] and [41]), the most important achievement of this research is that the proposed technology of integrated 
Table 2 Production parameters

\begin{tabular}{lccc}
\hline & \multicolumn{3}{l}{ Stage } \\
\cline { 2 - 4 } Parameter & $j=1$ & $j=2$ & $j=3$ \\
\hline$\alpha_{j}$ & 0.02 & 0.01 & 0.05 \\
$\beta_{j}$ & 0.01 & 0.1 & 0.01 \\
$I_{j}$ (US\$) & 0.5 & 0.5 & 0.5 \\
$R_{j 1}$ (US\$) & 5 & 0 & 0 \\
$R_{j 2}$ (US\$) & 20 & 0 & 0 \\
$p_{j}$ (US\$) & 10 & 20 & 5 \\
$S_{j}$ (US\$) & 0 & -2 & 40 \\
$f_{j 1}$ & 0.2 & 0 & 0.5 \\
$f_{j 2}$ & 0.8 & 1 & 0.5 \\
\hline
\end{tabular}

planning of PM and part quality inspection activities results in a decrease in the total manufacturing cost of the SMSPL as this was predictable because of the inherent interconnectivity of these two types of operation. In the investigated example this saving is $26.94 \%$. If we define two approaches: Without PM (refers to the conventional IS) and With PM Possibility (refers to the proposed integrated planning), the objective function value for the Without PM approach is 51587 and by adding the implementation possibility of PM activities (i.e., the With PM Possibility approach), it decreases to 37689 (see Fig. 4), in which this will be a huge saving for a manufacturing company. Figure 4 also illustrates the different cost components when we applied the With PM Possibility and Without PM approaches for the
Table 3 The inspection (I) activities done in the SMSPL while applying the Without PM approach

\begin{tabular}{llll}
\hline & \multicolumn{2}{l}{ Stage } & 3 \\
\cline { 2 - 4 } Period & 1 & 2 & \\
\hline 1 & I & & \\
2 & I & I & \\
3 & I & I & \\
4 & I & I & I \\
5 & I & I & I \\
6 & I & & I \\
7 & I & & I \\
8 & & & I \\
9 & & & I \\
10 & & & I \\
11 & & & \\
12 & & & \\
\hline
\end{tabular}

SMSPL. As can be seen, the extreme cost differences refer to the scrap and production costs because when the Without $P M$ approach is applied, most of the time the production stages are in the downgraded state and produce and proceed much more defective items in comparison to the With PM Possibility approach. Although the With PM Possibility approach poses US\$ 1500 PM cost to the system, this cost acts as an investment and reduces the scrap and production costs in a way that the total manufacturing cost is decreased.

Tables 3 and 4 show the places and periods in which the PM and part quality inspection activities are done

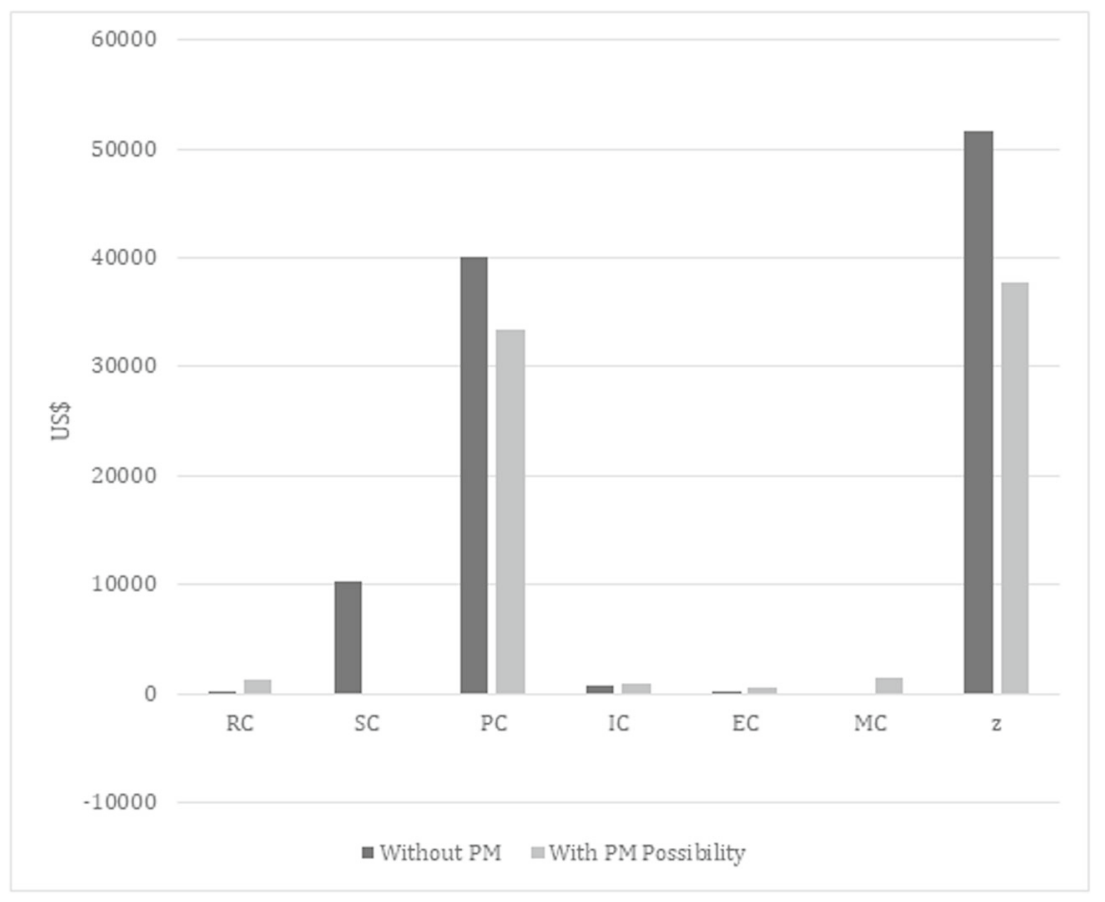

Fig. 4 Cost components of the adopted approaches 
Table 4 The maintenance (M) and inspection (I) activities done in the SMSPL while applying the With PM Possibility approach

\begin{tabular}{llll}
\hline & Stage & & \\
\cline { 2 - 4 } Period & 1 & 2 & 3 \\
\hline 1 & M,I & M & M \\
2 & I & I & M \\
3 & I & I & M \\
4 & I & I & M \\
5 & I & I & M \\
6 & I & I & M,I \\
7 & I & M & M \\
8 & I & I & M \\
9 & I & I & M \\
10 & I & & M,I \\
11 & I & M,I & M \\
12 & I & & M,I \\
\hline
\end{tabular}

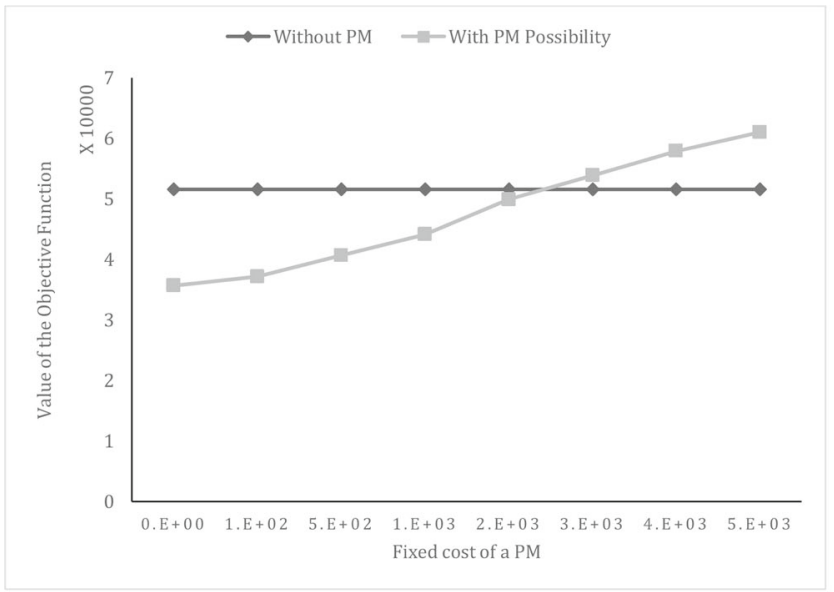

(a) Fixed cost of a PM. when the Without PM and With PM Possibility approaches are employed, respectively. Table 3 indicates that, for the Without PM approach, the majority of inspection activities are performed for the last stage because of its high scrap cost. However, when With PM Possibility approach is adopted (see Table 4), the model decides to establish inspection stations when and where the PM activities are not taken to be done. The reason for the PM activities done mostly for the last stage is that the scrap cost for the last stage is too high in comparison with the other stages and the model avoided a considerable waste of money.

The obtained solution of the presented model and accordingly the associated saving cost highly depend on the fixed and the variable cost of PM. As shown in Fig. 5a, by increasing the fixed cost of PM, the cost saving is being decreased as there is not any monetary benefit of applying the proposed integrated approach when the fixed cost of a PM is higher than 3000. However, "3000" unit cost for a PM seems unrealistic because it is 20 times more

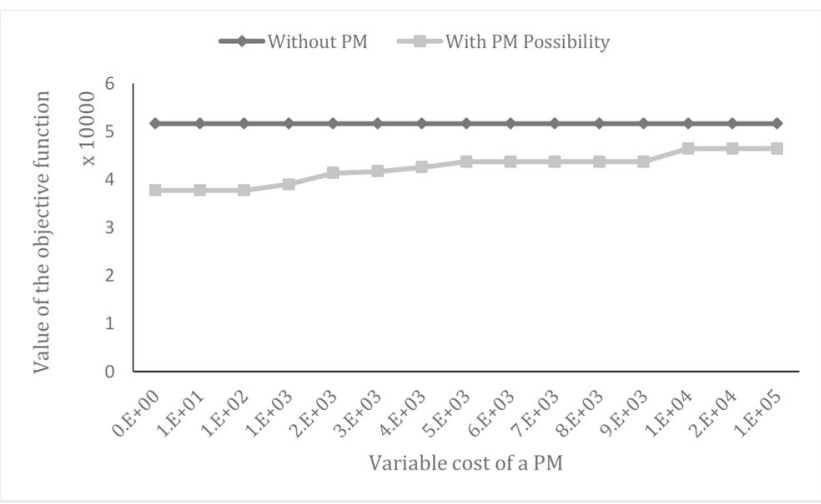

(b) Variable cost of a PM.

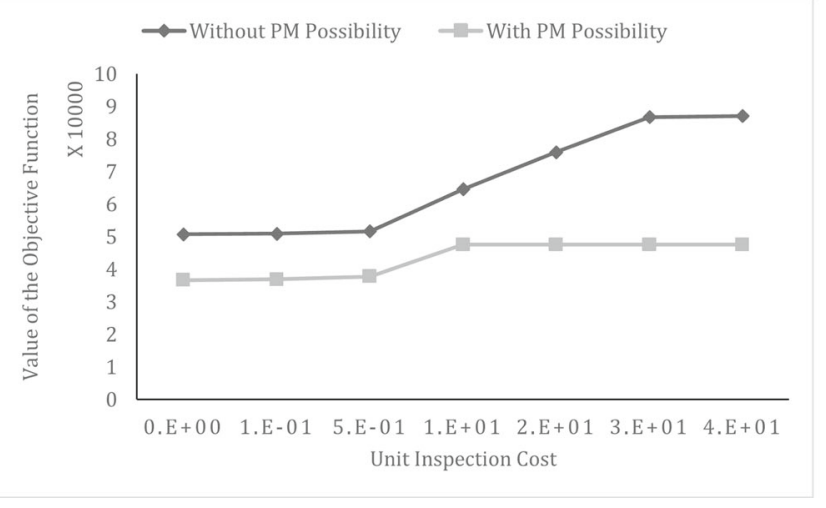

(c) Unit inspection cost.

Fig. 5 Objective function values by considering different values for the cost parameters 


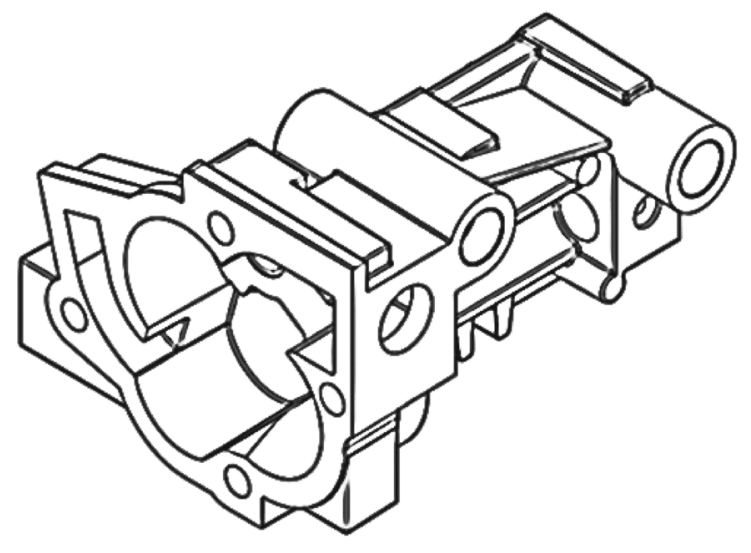

(a) Solid frame.

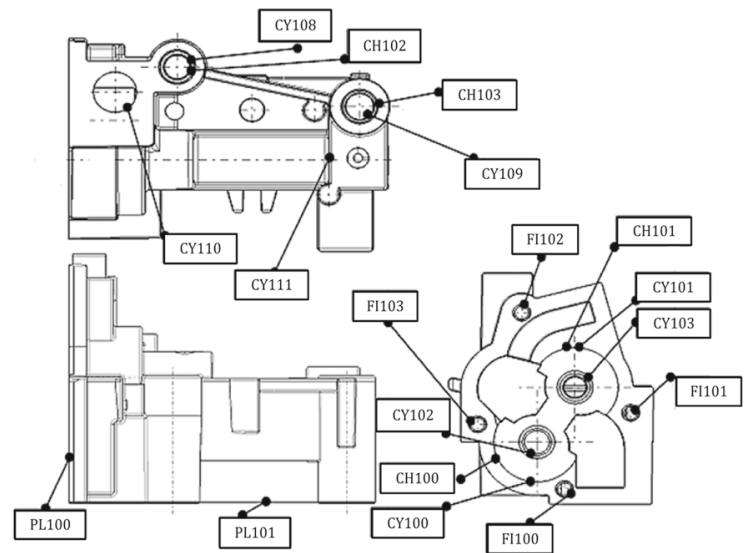

(b) Quality characteristics.

Fig. 6 Considered oil pump housing

Table 5 Production parameters of the case study

\begin{tabular}{|c|c|c|c|c|c|c|c|}
\hline \multirow[b]{2}{*}{$j$} & \multirow[b]{2}{*}{ Operation name } & \multicolumn{6}{|c|}{ Parameters } \\
\hline & & $a_{j}$ & $b_{j}$ & $\alpha_{j}$ & $\beta_{j}$ & $p_{j}(\mathrm{US} \$)$ & $S_{j}(\mathrm{US} \$)$ \\
\hline 1 & Rough milling PL100 & $6.79 \mathrm{e}-6$ & 0.00125 & 0.0027 & 0.00005 & 0.308333 & 1 \\
\hline 2 & Rough milling PL100 & $6.79 \mathrm{e}-6$ & 0.00125 & 0.0027 & 0.00005 & 0.345833 & 1 \\
\hline 3 & Rough milling PL101 & $6.35 \mathrm{e}-7$ & 0.00954 & 0.0027 & 0.00005 & 0.277083 & 1 \\
\hline 4 & Boring CY110 & $6.60 \mathrm{e}-5$ & 0.00898 & 0.0027 & 0.00005 & 0.320833 & 1 \\
\hline 5 & Rough drilling CY108 and CY109 & $6.35 \mathrm{e}-7$ & 0.00954 & 0.0027 & 0.00005 & 0.1875 & 1 \\
\hline 6 & Chamfering CY108 and CY109 & $6.35 \mathrm{e}-7$ & 0.00954 & 0.0027 & 0.00005 & 0.520833 & 1 \\
\hline 7 & Chamfering CY100 and CY101 & $3.18 \mathrm{e}-4$ & 0.00328 & 0.0027 & 0.00005 & 0.535417 & 1 \\
\hline 8 & Boring CY100 & $3.18 \mathrm{e}-4$ & 0.00328 & 0.0027 & 0.00005 & 0.535417 & 1 \\
\hline 9 & Boring CY101 & $9.61 \mathrm{e}-5$ & 0.00768 & 0.0027 & 0.00005 & 0.254167 & 1 \\
\hline 10 & Rough drilling CY102 and CY103 & $2.66 \mathrm{e}-5$ & 0.00814 & 0.0027 & 0.00005 & 0.227083 & 1 \\
\hline 11 & Rough drilling CY111 & $2.66 \mathrm{e}-5$ & 0.00814 & 0.0027 & 0.00005 & 0.279167 & 1 \\
\hline 12 & Boring CY108 and CY109 & $9.66 \mathrm{e}-4$ & 0.00811840 & 0.0027 & 0.00005 & 0.254167 & 1 \\
\hline 13 & Boring CY102 and CY103 & $2.69 \mathrm{e}-3$ & 0.00891236 & 0.0027 & 0.00005 & 0.254167 & 1 \\
\hline 14 & Boring CY111 & $6.60 \mathrm{e}-5$ & 0.00507278 & 0.0027 & 0.00005 & 0.24375 & 1 \\
\hline 15 & Finish milling PL100 & $6.60 \mathrm{e}-5$ & 0.00507278 & 0.0027 & 0.00005 & 0.26875 & 1 \\
\hline$j$ & Operation name & $q_{j}$ & $l_{j}$ & $f_{1 j}$ & $f_{2 j}$ & $R_{1 j}(\mathrm{US} \$)$ & $R_{2 j}(\mathrm{US} \$)$ \\
\hline 1 & Rough milling PL100 & 2.50 & 0.16 & 0.97 & 0.03 & 0.030833 & 0.061667 \\
\hline 2 & Rough milling PL100 & 2.50 & 0.16 & 0.75 & 0.25 & 0.034583 & 0.069167 \\
\hline 3 & Rough milling PL101 & 2.50 & 0.16 & 0.33 & 0.67 & 0.027708 & 0.055417 \\
\hline 4 & Boring CY110 & 3.00 & 0.10 & 0.08 & 0.92 & 0.032083 & 0.064167 \\
\hline 5 & Rough drilling CY108 and CY109 & 3.40 & 0.12 & 0.87 & 0.13 & 0.01875 & 0.0375 \\
\hline 6 & Chamfering CY108 and CY109 & 2.90 & 0.15 & 0.42 & 0.58 & 0.052083 & 0.104167 \\
\hline 7 & Chamfering CY100 and CY101 & 2.90 & 0.15 & 0.69 & 0.31 & 0.053542 & 0.107083 \\
\hline 8 & Boring CY100 & 3.00 & 0.10 & 0.88 & 0.12 & 0.053542 & 0.107083 \\
\hline 9 & Boring CY101 & 3.00 & 0.10 & 0.05 & 0.95 & 0.025417 & 0.050833 \\
\hline 10 & Rough drilling CY102 and CY103 & 3.40 & 0.12 & 0.90 & 0.10 & 0.022708 & 0.045417 \\
\hline 11 & Rough drilling CY111 & 3.40 & 0.12 & 0.91 & 0.09 & 0.027917 & 0.055833 \\
\hline 12 & Boring CY108 and CY109 & 3.00 & 0.10 & 0.44 & 0.56 & 0.025417 & 0.050833 \\
\hline 13 & Boring CY102 and CY103 & 3.00 & 0.10 & 0.41 & 0.59 & 0.025417 & 0.050833 \\
\hline 14 & Boring CY111 & 3.00 & 0.10 & 0.02 & 0.98 & 0.024375 & 0.04875 \\
\hline 15 & Finish milling PL100 & 27 & 150 & 0.30 & 0.70 & 0.026875 & 0.05375 \\
\hline
\end{tabular}




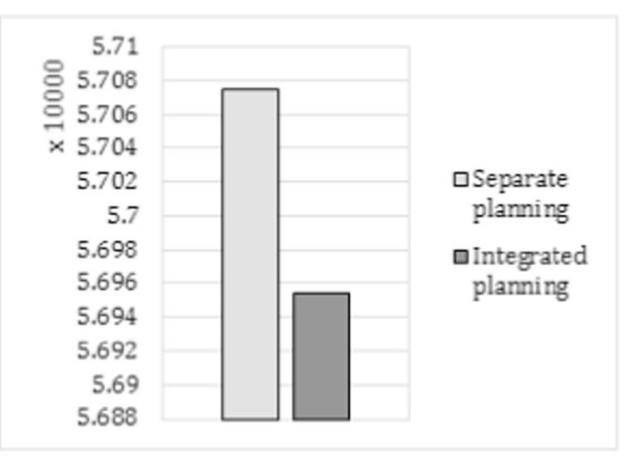

(a) Total cost (US\$).

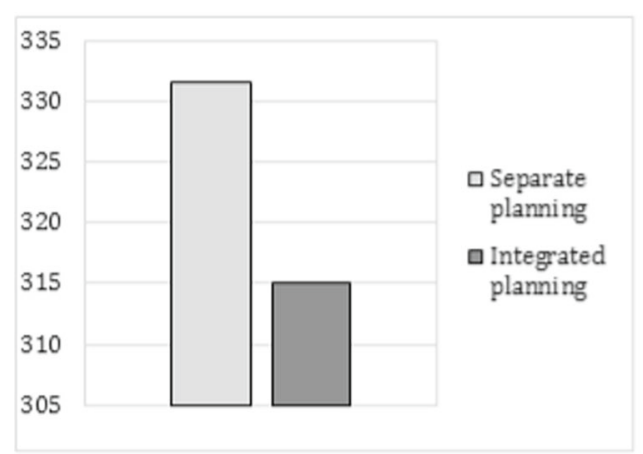

(c) Scrap cost (US\$).

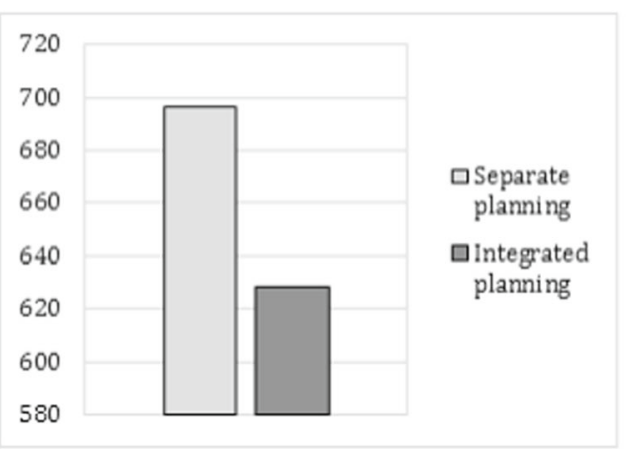

(e) Inspection cost (US\$).

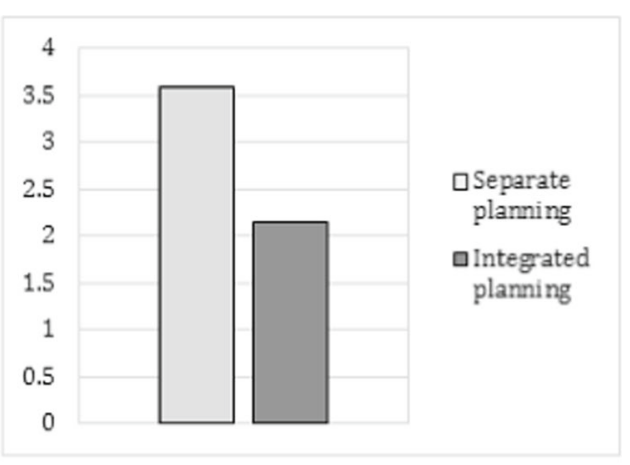

(b) Replacement cost (US\$).

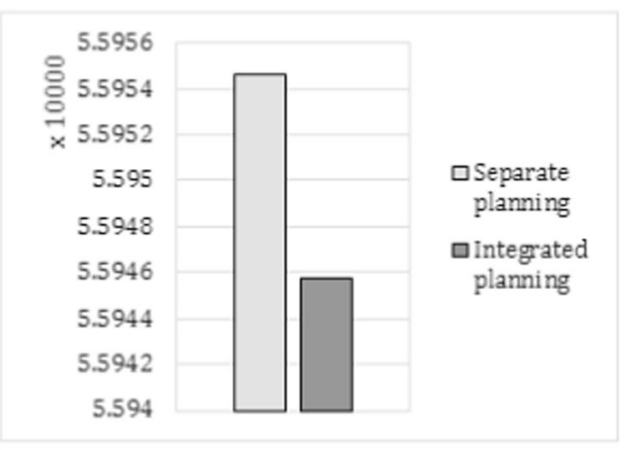

(d) Production cost (US\$).

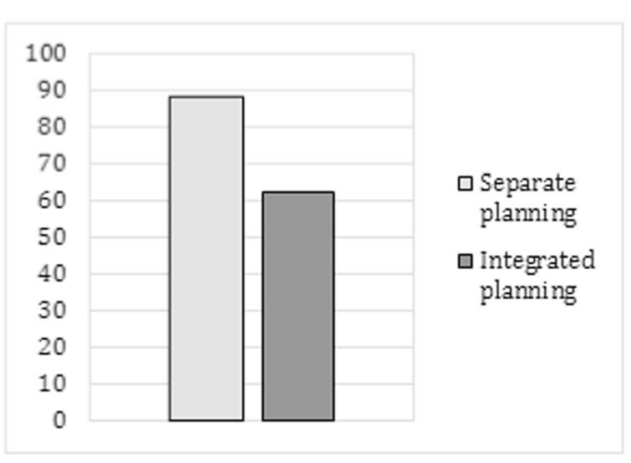

(f) PM cost (US\$).

Fig. 7 Cost components of the SMSPL of the oil pump

than "150" unit cost which we have inspired from the real case. The impact of changing the variable cost of a PM is also investigated. This kind of expense can be related to the required material and generally, it is being changed regarding the situation of machine. Figure $5 \mathrm{~b}$ shows the sensitivity of the objective function to the changes of the variable $\mathrm{PM}$ cost. By increasing the variable PM cost, the total cost goes up. However, when the value of the variable PM cost is considered equal and more than 1000 , the total cost does not increase and it is not sensitive because the model decides to do PM activity for all the stages in all the periods.
The other critical parameter for the SMSPL system is the unit inspection cost. Figure $5 \mathrm{c}$ depicts the objective function values when the unit cost of inspection changes. As can be seen, the With PM Possibility approach is the cost-effective approach even when there is no cost for inspection. In addition, the cost saving of the With PM Possibility approach increases when the unit inspection cost is being raised, so the With PM Possibility approach is more cost-effective whenever the unit cost of inspection is higher. Please note that after " 10 " unit inspection cost, the value of the objective function under the With PM Possibility approach does not 
Table 6 Places and periods in which inspection (I) and preventive maintenance (M) activities are performed by applying two different approaches

\begin{tabular}{|c|c|c|c|c|c|c|c|c|c|c|c|c|c|c|c|}
\hline \multirow{2}{*}{$\begin{array}{l}\text { Integrated planning } \\
\text { Period }\end{array}$} & \multicolumn{15}{|c|}{ Stage } \\
\hline & 1 & 2 & 3 & 4 & 5 & 6 & 7 & 8 & 9 & 10 & 11 & 12 & 13 & 14 & 15 \\
\hline 1 & M & M & M & M,I & M & M & M & M & M,I & M & M & M & M & M & M,I \\
\hline 2 & & & & I & & & & & I & & & & & & I \\
\hline 3 & & & & I & & & & & I & & & & & & I \\
\hline 4 & & & & I & & & & & I & & & & & & I \\
\hline 5 & & & & I & & & & & I & & & M & & & I \\
\hline 6 & & & & I & & & & & I & & & & M & & I \\
\hline 7 & & & & I & & & & & I & & & & & & I \\
\hline 8 & & & & I & & & & & I & & & & & & I \\
\hline 9 & & & & I & & & & & I & & & & M & & I \\
\hline 10 & & & & I & & & & & I & & & & M & & I \\
\hline 11 & & & & I & & & & & I & & & M & & & I \\
\hline 12 & & & & I & & & & & I & & & & M & & I \\
\hline \multicolumn{16}{|l|}{ Separate planning } \\
\hline Period & 1 & 2 & 3 & 4 & 5 & 6 & 7 & 8 & 9 & 10 & 11 & 12 & 13 & 14 & 15 \\
\hline 1 & $\mathrm{M}$ & M & M & M,I & $\mathrm{M}$ & $\mathrm{M}$ & M & $\mathrm{M}$ & $\mathrm{M}, \mathrm{I}$ & M & $\mathrm{M}$ & $\mathrm{M}$ & M & M & M,I \\
\hline 2 & & & & I & & & & & I & & & & & & I \\
\hline 3 & & & & I & & & & & I & & & & & & I \\
\hline 4 & & & & I & & & & & I & & & & & & I \\
\hline 5 & & & & I & & & & & I & & & I & & & I \\
\hline 6 & $\mathrm{M}$ & M & M & M,I & M & M & M & M & M,I & M & M & $\mathrm{M}$ & M & $\mathrm{M}$ & M,I \\
\hline 7 & & & & I & & & & & I & & & & & & I \\
\hline 8 & & & & I & & & & & I & & & & & & I \\
\hline 9 & & & & I & & & & & I & & & & & & I \\
\hline 10 & & & & I & & & & & I & & & I & & & I \\
\hline 11 & & & & I & & I & & & I & & & & & & I \\
\hline 12 & & & & I & & & & & I & & I & & & & I \\
\hline
\end{tabular}

change because Model 2 decides not to do any inspection activity.

\section{Case study}

This section provides a real case study within the automotive industry in France to verify the proposed Model 2 and applied solution approach. A manufacturer of oil pump housings in the supply chain of "Renault Groupe" is selected. This part includes 15 quality characteristics, which are processed along 15 production stages. Figure 6a shows the solid frame of the part and 15 quality characteristics are indicated in Fig. 6b. The data of this case study regarding the proposed Model 2 are provided in Table 5. The planning horizon for this SMSPL is 12 periods (i.e., 12 months) and unit inspection cost is estimated US\$ 0.018. The requested minimum AOQL is 900 units. The PM cost is a linear function of $\omega_{t j}, m c_{t j}=l_{j} \omega_{t j}+q_{j}$. In the past, the planning of inspection and PM activities were optimized separately.
In this regard, the maintenance department was doing a PM activity for each stage in the beginning of the first and sixth periods. Now, the system benefits from the integrated planning of the part quality inspection and PM activities, which is provided by applying the proposed Model 2 . Henceforth, we name these two different approaches as separate and integrated planning.

In this section, we aim at comparing the performance of this SMSPL before and after applying the proposed integrated planning. For this purpose, some key performance indicators and cost components are regarded. Figure 7 shows the comparison of the different cost components when the system used the separate and integrated planning approach. As can be seen, all the cost components are improved after applying the integrated planning approach. It is notable that both approaches delivered no non-conforming items to customers. Table 6 shows the places and periods, in which the part quality inspection and PM activities are performed. Integrated planning not only reduced the number of inspection and PM activities, 
Table 7 Places and periods in which inspection (I) and preventive maintenance (M) activities are performed by applying the two different approaches while considering the revenue

\begin{tabular}{|c|c|c|c|c|c|c|c|c|c|c|c|c|c|c|c|}
\hline \multirow{2}{*}{$\begin{array}{l}\text { Integrated planning } \\
\text { Period }\end{array}$} & \multicolumn{15}{|c|}{ Stage } \\
\hline & 1 & 2 & 3 & 4 & 5 & 6 & 7 & 8 & 9 & 10 & 11 & 12 & 13 & 14 & 15 \\
\hline 1 & M & M & M & M,I & M & M & M & M & M & M & M,I & M & M & M & M,I \\
\hline 2 & & & & & & & & & & & I & M & & & I \\
\hline 3 & & & & & & & & & & & I & M & & & I \\
\hline 4 & & & & & & & & & & & I & M & & & I \\
\hline 5 & & & & & & & & & & & I & M & & & I \\
\hline 6 & & & & & & & & & & & I & M & & & I \\
\hline 7 & & & & & & & M & M & & & I & M & & & I \\
\hline 8 & & & & & & & & & & & I & M & & & I \\
\hline 9 & & & & & & & & & & & I & M & & & I \\
\hline 10 & & & & & & & & & & & I & M & & & I \\
\hline 11 & & & & & & & & & & & I & M & & & I \\
\hline 12 & & & & & & & & & & & I & M & & & I \\
\hline \multicolumn{16}{|l|}{ Separate planning } \\
\hline Period & 1 & 2 & 3 & 4 & 5 & 6 & 7 & 8 & 9 & 10 & 11 & 12 & 13 & 14 & 15 \\
\hline 1 & M & M & $\mathrm{M}$ & M,I & $\mathrm{M}$ & $\mathrm{M}$ & $\mathrm{M}$ & $\mathrm{M}$ & $\mathrm{M}$ & $\mathrm{M}$ & M,I & $\mathrm{M}$ & $\mathrm{M}$ & $\mathrm{M}$ & M,I \\
\hline 2 & & & & & & & & & & & I & & & & I \\
\hline 3 & & & & & & & & & & & I & & & & I \\
\hline 4 & & & & & & & & & & & I & & & & I \\
\hline 5 & & & & & & & & & & & I & & & & I \\
\hline 6 & $\mathrm{M}$ & $\mathrm{M}$ & $\mathrm{M}$ & M,I & $\mathrm{M}$ & $\mathrm{M}$ & $\mathrm{M}$ & $\mathrm{M}$ & $\mathrm{M}$ & $\mathrm{M}$ & M,I & $\mathrm{M}$ & $\mathrm{M}$ & $\mathrm{M}$ & M,I \\
\hline 7 & & & & & & & & & & & I & & & & I \\
\hline 8 & & & & & & & & & & & I & & & & I \\
\hline 9 & & & & & & & & & & & I & & & & I \\
\hline 10 & & & & & & & & & & & I & & & & I \\
\hline 11 & & & & & & & & & & & I & & & & I \\
\hline 12 & & & & & & & & & & & I & & & & I \\
\hline
\end{tabular}

but also decreased the total cost while satisfying the minimum number of required outgoing conforming items, 900 units. Noteworthy, instead of performing PM activities for all the stages (i.e., separate planning), the integrated planning approach focuses on the two most quick-deteriorating stages (i.e., stages \#12 and \#13) for doing PM activities.

Although applying the integrated planning approach reduced the total cost, it produced fewer conforming items, $0.11 \%$ less. To overcome this lack, a new mathematical term entitled "Revenue," which calculates earned money from selling conforming products, is added to the objective function. Thus, we change the total cost objective (21) to the following new term (52), where $S P$ is the sale price for each conforming product. In this case study, the values of $S P$ and $C$ are equal to US\$ 10 and US\$20, respectively.

$$
\begin{aligned}
\operatorname{Min} z= & R C+S C+P C+I C+M C+E C \\
& -\sum_{t=1}^{T} S P \times w_{t, 15,1}
\end{aligned}
$$

Model 2 with the new objective function (52) was run on the data of the case study. The new results are shown through Table 7 and Fig. 8. As can be seen in Table 7, Model 2 has employed more PM activities instead of the inspection. Actually, although using inspection prevents the delivery of non-conforming items to customers, it removes a lot of items along the SMSPL because of the incurred defects (i.e., scraps). But, employing PMs raises the number of right processed items after the production stages, and therefore, the total number of delivered conforming items is increased. Obviously, increasing the number of employed PM activities not only raises the PM cost, but also causes processing more items along the SMSPL and accordingly imposes much more production cost (see Fig. 8). On the other side, employing fewer inspection activities results in the less inspection and its related costs (i.e., scrap and replacement costs) (see Fig. 8).

In conclusion, through the usage of the new objective function (52), the number of produced conforming items was raised (i.e., $0.64 \%$ more) and this made more income 


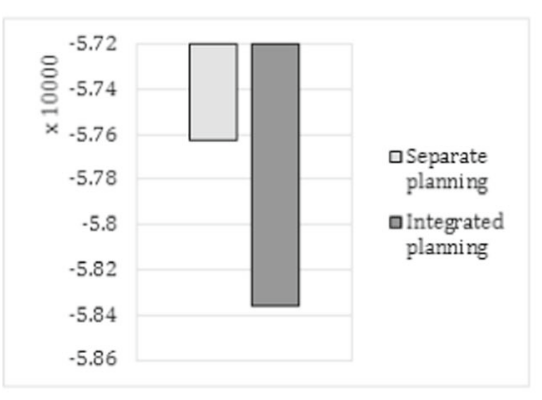

(a) New objective function.

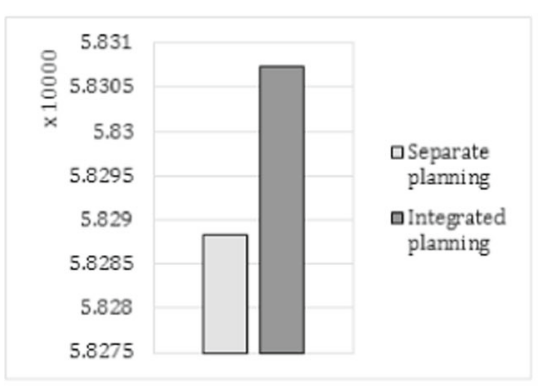

(c) Total cost (US\$).

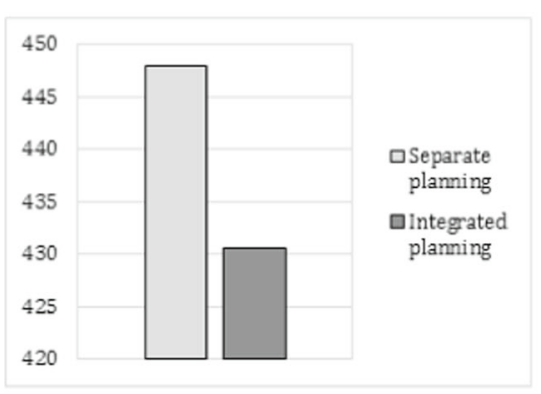

(e) Inspection cost (US\$).

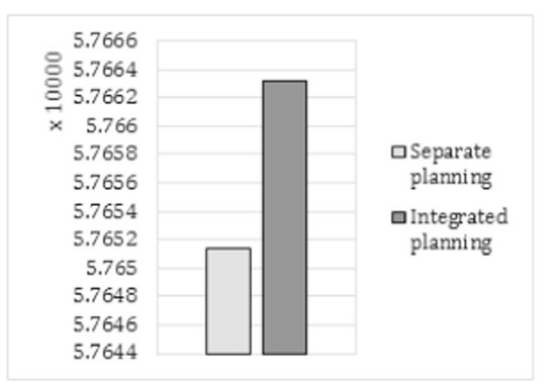

(g) Production cost (US\$).

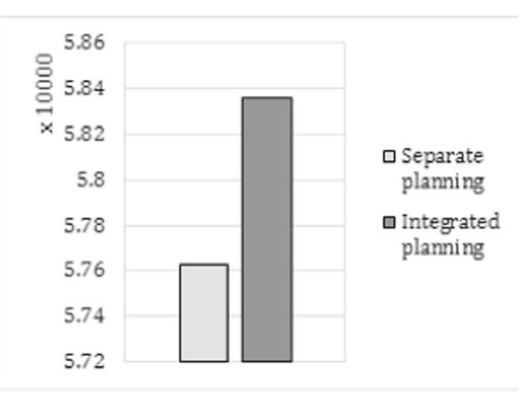

(b) Income (US\$).

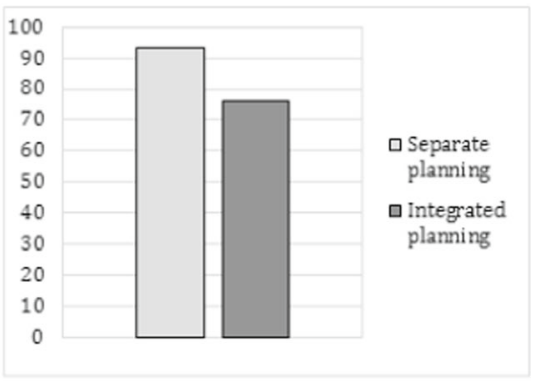

(d) Scrap cost (US\$).

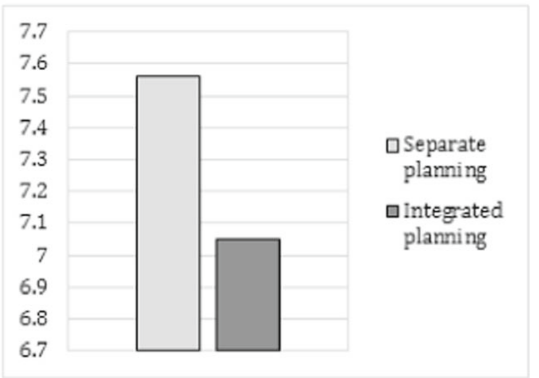

(f) Replacement cost (US\$).

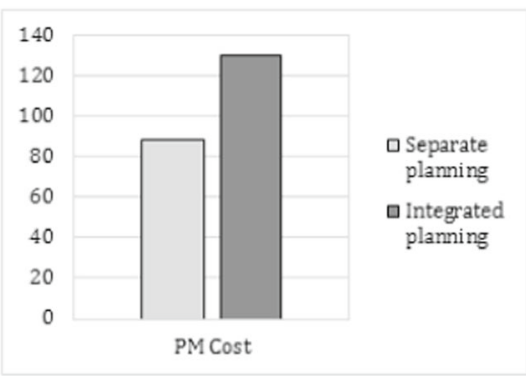

(h) PM cost (US\$).

Fig. 8 Cost components of the SMSPL of the oil pump by considering a new objective function

(revenue-totalcost), which is the main purpose of the company.

\section{Conclusion and future research direction}

This paper has developed a mixed-integer mathematical programming model for the integrated planning problem of the part quality inspection and PM activities in deteriorating serial multi-stage manufacturing systems. It has been assumed that each production stage is deteriorating in time and consequently the probability of a conforming item acquires a defect in each stage is increasing. The proposed model determines the optimum time and place for the PM and part quality inspection activities while minimizing the total manufacturing cost including repair, scrap, production, 
inspection, PM, and warranty cost. A serial three-stage manufacturing system as a numerical example has been explored through the proposed approach and the obtained results have indicated that the concurrent planning of the $\mathrm{PM}$ and part quality inspection activities decreases the total manufacturing cost extremely (nearly $27 \%$ ). In addition, a real case in automotive industry has been investigated. By applying of the presented approach, the efficiency of the company has been improved; especially, it increased the average of outgoing quality level. The previously developed mathematical models in the literature have been solved through non-exact solution methodologies (i.e., heuristic and metaheuristic algorithms). In this regard, although incorporating the deterioration behavior of production stages posed too much complexity into the first proposed MINLP model, we have linearized it to an MILP which can be optimally solved by the most of commercial software, such as GAMS.

In this paper, it was assumed that the life time of each production stage was known and thus, the downtime is certain. However, it does not seem a real assumption and the downtime has a stochastic behavior. Hence, for future research, it is highly recommended to incorporate this stochastic behavior to the mathematical model.

Acknowledgments The authors would like to acknowledge France embassy in Iran and Campus France, the French national agency for the promotion of higher education, international student services and international mobility, for their financial support under the scholarship number 906221A.

\section{References}

1. Mandroli SS, Shrivastava AK, Ding Y (2006) A survey of inspection strategy and sensor distribution studies in discrete-part manufacturing processes. IIE Trans 38(4):309-328

2. Sahnoun M, Bettayeb B, Bassetto SJ, Tollenaere M (2016) Simulation-based optimization of sampling plans to reduce inspections while mastering the risk exposure in semiconductor manufacturing. J Intell Manuf 27(6):1335-1349

3. Shetwan AG, Vitanov VI, Tjahjono B (2011) Allocation of quality control stations in multistage manufacturing systems. Comput Ind Eng 60(4):473-484

4. Raz T (1986) A survey of models for allocating inspection effort in multistage production systems. J Qual Technol 18(4):239-247

5. Colledani M, Tolio T, Fischer A, Iung B, Lanza G, Schmitt R, Váncza J (2014) Design and management of manufacturing systems for production quality. CIRP Ann - Manuf Technol 63(2):773-796

6. Lindsay GF, Bishop AB (1964) Allocation of screening inspection effort-a dynamic-programming approach. Manag Sci 10(2):342352

7. Shi J, Zhou S (2009) Quality control and improvement for multistage systems: a survey. IIE Trans 41(9):744-753

8. Rezaei-Malek M, Mohammadi M, Dantan JY, Siadat A, Tavakkoli-Moghaddam R (2018) A review on optimization of part quality inspection planning in a multi-stage manufacturing system. Int J Prod Res (to be apeared)
9. Emmons H, Rabinowitz G (2002) Inspection allocation for multistage deteriorating production systems. IIE Trans 34(12):10311041

10. Zheng S (2000) Dynamic quality control in assembly systems. IIE Trans 32(9):797-806

11. Azadeh A, Sangari MS, Sangari E, Fatehi S (2015) A particle swarm algorithm for optimising inspection policies in serial multistage production processes with uncertain inspection costs. Int J Comput Integr Manuf 28(7):766-780

12. Muchiri PN, Pintelon L, Martin H, Chemweno P (2014) Modelling maintenance effects on manufacturing equipment performance: results from simulation analysis. Int J Prod Res 52(11):3287-3302

13. Liu Q, Dong M, Lv W, Ye C (2017) Manufacturing system maintenance based on dynamic programming model with prognostics information. Journal of Intelligent Manufacturing, pp 1-19 https://doi.org/10.1007/s10845-017-1314-6

14. Nicolai RP, Dekker R (2008) Optimal maintenance of multicomponent systems: a review. Springer, London, pp 263-286

15. Iung B, Levrat E, Marquez AC, Erbe H (2009) Conceptual framework for e-maintenance: illustration by e-maintenance technologies and platforms. Ann Rev Control 33(2):220-229

16. Kuo Y (2006) Optimal adaptive control policy for joint machine maintenance and product quality control. Eur J Oper Res 171(2):586-597

17. Mohammadi M, Siadat A, Dantan JY, Tavakkoli-Moghaddam R (2015) Mathematical modelling of a robust inspection process plan: Taguchi and Monte Carlo methods. Int J Prod Res 53(7):2202-2224

18. Rezaei-Malek M, Tavakkoli-Moghaddam R, Siadat A, Dantan JY (2017) Integrated preventive maintenance and inspection planning in a deteriorating serial multi-stage manufacturing system. In: Proceedings of the 7 th International Conference on Industrial Engineering and Systems Management, pp 352-357

19. Penn M, Raviv T (2008) A polynomial time algorithm for solving a quality control station configuration problem. Discret Appl Math 156(4):412-419

20. Rau H, Chu YH, Cho KH (2005) Layer modelling for the inspection allocation problem in re-entrant production systems. Int J Prod Res 43(17):3633-3655

21. Korytkowski P (2011) A genetic algorithm with tournament selection for optimising inspection allocation in multiproduct multistage production systems. Int J Simul Process Modell 6(3):238-244

22. Ercan SS, Hassan MZ, Taulananda A (1974) Cost minimizing single sampling plans with AIQL and AOQL constraints. Manag Sci 20(7):1112-1121

23. Bai DS, Yun HJ (1996) Optimal allocation of inspection effort in a serial multi-stage production system. Comput Ind Eng 30(3):387396

24. Jang W, Shanthikumar JG (2002) Stochastic allocation of inspection capacity to competitive processes. Naval Res Logist 49(1):78-94

25. Rebello R, Agnetis A, Mirchandani PB (1995) Specialized inspection problems in serial production systems. Eur J Oper Res 80(2):277-296

26. Shiau YR (2003) Inspection allocation planning for a multiple quality characteristic advanced manufacturing system. Int $\mathbf{J}$ Adv Manuf Technol 21(7):494-500

27. Shiau YR (2003) Quick decision-making support for inspection allocation planning with rapidly changing customer requirements. Int J Adv Manuf Technol 22(9):633-640

28. Shiau YR, Lin MH, Chuang WC (2007) Concurrent process/inspection planning for a customized manufacturing system based on genetic algorithm. Int J Adv Manuf Technol 33(7):746755 
29. Taneja M, Viswanadham N (1994) Inspection allocation in manufacturing systems: a genetic algorithm approach. In: Proceedings of the 1994 IEEE International Conference on Robotics and Automation, vol 4, pp 3537-3542

30. White LS (1969) Shortest route models for the allocation of inspection effort on a production line. Manag Sci 15(5):249259

31. Vaghefi A, Sarhangian V (2009) Contribution of simulation to the optimization of inspection plans for multi-stage manufacturing systems. Comput Ind Eng 57(4):1226-1234

32. Deliman NC, Feldman RM (1996) Optimization of process improvement and inspection location for serial manufacturing. Int J Prod Res 34(2):395-405

33. Kim J, Gershwin SB (2008) Analysis of long flow lines with quality and operational failures. IIE Trans 40(3):284-296

34. Tayi GK, Ballou DP (1988) An integrated production-inventory model with reprocessing and inspection. Int $\mathrm{J}$ Prod Res 26(8):1299-1315
35. Freiesleben $\mathbf{J}$ (2006) Costs and benefits of inspection systems and optimal inspection allocation for uniform defect propensity. Int $\mathbf{J}$ Qual Reliab Manag 23(5):547-563

36. Tannock J, Saelem S (2007) Manufacturing disruption costs due to quality loss. Int J Qual Reliab Manag 24(3):263-278

37. Yum BJ, McDowellj ED (1987) Optimal inspection policies in a serial production system including scrap rework and repair: An milp approach. Int J Prod Res 25(10):1451-1464

38. Madu CN (2000) Competing through maintenance strategies. Int J Qual Reliab Manag 17(9):937-949

39. Williams HP (2013) Model building in mathematical programming. Wiley, NY

40. Belotti P, Kirches C, Leyffer S, Linderoth J, Luedtke J, Mahajan A (2013) Mixed-integer nonlinear optimization. Acta Numer 22:1-131

41. Mohammadi M, Dantan JY, Siadat A, Tavakkoli-Moghaddam $\mathrm{R}$ (2017) A bi-objective robust inspection planning model in a multi-stage serial production system. Int J Prod Res 0(0):1-26. https://doi.org/10.1080/00207543.2017.1363425 